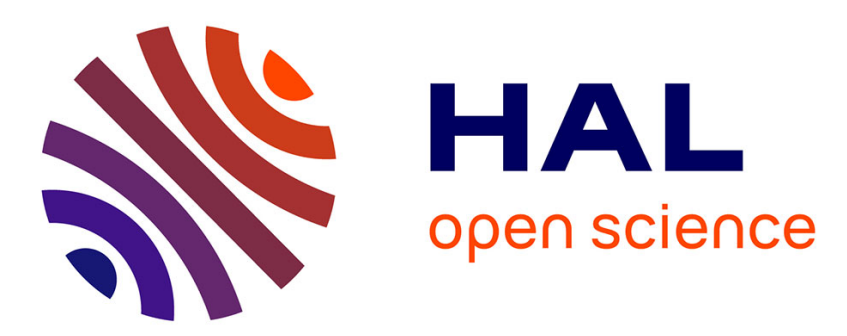

\title{
Photorefractive effect in GaAs at low temperature: influence of the metastable state of the EL2 defect \\ Philippe Delaye, B. Sugg
}

\section{To cite this version:}

Philippe Delaye, B. Sugg. Photorefractive effect in GaAs at low temperature: influence of the metastable state of the EL2 defect. Optical Materials, 1995, 4 (2-3), pp.256-261. 10.1016/09253467(94)00070-0 . hal-00677570v2

\section{HAL Id: hal-00677570 \\ https://hal-iogs.archives-ouvertes.fr/hal-00677570v2}

Submitted on 30 Mar 2012

HAL is a multi-disciplinary open access archive for the deposit and dissemination of scientific research documents, whether they are published or not. The documents may come from teaching and research institutions in France or abroad, or from public or private research centers.
L'archive ouverte pluridisciplinaire HAL, est destinée au dépôt et à la diffusion de documents scientifiques de niveau recherche, publiés ou non, émanant des établissements d'enseignement et de recherche français ou étrangers, des laboratoires publics ou privés. 


\title{
PHOTOREFRACTIVE EFFECT IN GaAs AT LOW TEMPERATURE : INFLUENCE OF THE METASTABLE STATE OF THE EL2 DEFECT
}

\author{
Ph. Delaye(1,2), B. Sugg(2)
}

(1) Institut d'Optique Théorique et Appliquée, Unité de Recherche Associée 14 au Centre National de la Recherche Scientifique, Bât.503, Centre Scientifique d'Orsay, B.P. 147, 91403 Orsay Cedex. Tel: 33169416850, Fax: 33169413192, Email: philippe.delaye@iota.u-psud.fr (2) Fachbereich Physik der Universität Osnabrück, 49069 Osnabrück, Germany

\begin{abstract}
We present here a theoretical and experimental analysis of photorefractive twobeam coupling in undoped GaAs as a function of temperature. Three major features are experimentally observed, firstly, a change of sign of the photorefractive beam coupling gain around $150 \mathrm{~K}$, secondly, an enhancement of the space charge field by a factor 2 compared to the diffusion field and, finally, a strong peak of the absorption grating amplitude around $150 \mathrm{~K}$. A photorefractive model is established that includes the metastable state of the EL2 defect with its optical properties (optical generation and optical recovery). It predicts all observed features correctly and is in good agreement with the experimental data.
\end{abstract}

Introduction. Important parameters which influence the photorefractive effect (PRE) are the nature and the characteristics of the deep defect in which carriers are redistributed. Its concentration and occupancy ratio as well as its optical cross-sections greatly influence the strength of the PRE. A lot of studies are currently performed in order to identify the deep level involved in the PRE in different materials sensitive to the infrared $(\mathrm{GaAs}[1], \operatorname{InP}[2,3]$, CdTe[4]). To that purpose an optical contactless technique was proposed : the Deep Level Photodiffractive Spectroscopy (DLPS) [5]. In this technique the study of the variation of the strength of the PRE with temperature gives information on the deep levels present in the sample. This technique was used for InP:Fe to deduce the presence of a secondary defect that influences the PRE [3]. In undoped GaAs, due to peculiar metastability properties of the EL2 defect, drastic variation of the PRE at low temperature were expected and experimentally observed [6,7]. The aim of this paper is to present both experimental and theoretical investigations performed in GaAs:EL2 with the DLPS technique.

Set-up and sample. We performed two-beam coupling experiments with a semi-insulating GaAs sample. Two s-polarized beams of a diode pumped Nd:YLF laser (emitting at $1.047 \mu \mathrm{m}$ ) interfere on the crystal (propagations along [ $\overline{1} 10]$ direction) and create a PR grating with a grating vector $\mathrm{k}$ along [001] (grating spacing $\Lambda=3 \mu \mathrm{m}$ ). The typical total illumination used in the experiment was $60 \mathrm{~mW} . \mathrm{cm}^{-2}$ inside the crystal. The PRE creates a refractive index grating leading to an energy transfer from the pump beam towards the probe beam we measure. In order to separate the photorefractive gain $\Gamma$ from an eventual absorption grating component we use the symmetry of the PRE. In the configuration we use, turning the crystal by $180^{\circ}$ around the [110] axis changes the sign of $\Gamma$, whereas the absorption grating $\Delta \alpha$ keeps the same sign. Thus measurements in both orientations allow to separate the 
photorefractive gain $\Gamma$ from the absorption grating $\Delta \alpha$. In all our experimental measurements we make this treatment and present directly $\Gamma$ and $\Delta \alpha$. The sample was placed in a liquid nitrogen cryostat and cooled under illumination. In order to avoid the vibration induced by boiling nitrogen, the measurement was performed during warming-up of the cryostat, after all the nitrogen was evaporated. The temperature range of the experiment was $90-300 \mathrm{~K}$. The warming of the sample occured with a maximum rate of about $2 \mathrm{~K} \cdot \mathrm{min}^{-1}$. Around room temperature a resistor was used to heat the sample. The temperature was measured with a Nickel-Chromium thermocouple placed on the sample carrier. The temperature variation was slow enough to allow the measurement of temperature at each instant when $\Gamma$ and $\Delta \alpha$ were measured and to ensure that the sample was in thermal equilibrium. We used an undoped GaAs samples with high excess shallow acceptors and $\left[E L 2^{0}\right] \approx\left[E_{2} 2^{+}\right]$. Absorption, Electron Paramagnetic Resonance (EPR) and room temperature photorefractive measurements performed with this sample [1] gave [EL2] $=1.3 \times 10^{16} \mathrm{~cm}^{-3}$ and $\left[E L 2^{+}\right]=6 \times 10^{15} \mathrm{~cm}^{-3}$.

Experimental results. The behavior of the photorefractive gain $\Gamma$ is rather peculiar (Fig.1). Firstly, between $300 \mathrm{~K}$ and $150 \mathrm{~K}$ a small decrease corresponding to the decrease of the diffusion field with temperature is observed. At $150 \mathrm{~K}$ a strong decrease of the gain occurs followed by a change of sign. This reverse of the sign is followed by a peak of the gain $\Gamma$ centered around $140 \mathrm{~K}$, the maximum value being around $0.12-0.15 \mathrm{~cm}^{-1}$, a value that corresponds to a space charge field higher than the diffusion field. After this peak the gain decreases with temperature. When decreasing the illumination on the sample we observe a displacement of the peak of the gain of about $10 \mathrm{~K}$. The other effect we observe concerns the absorption part $\Delta \alpha$ of the beam coupling (Fig.2). The absorption grating is negligible at room temperature as expected in that type of materials and as observed previously [8]. At low temperature we see the appearance of a strong peak of the absorption part of the beam coupling centered at $140 \mathrm{~K}$. The absorption grating vanishes at lower temperature. All these features can not be explained by the electron hole competition model with only one defect EL2 that explains the PRE in GaAs at room temperature[1]. In order to explain these features we introduce a metastable state of the EL2 defect in the band transport model that is known to appear in GaAs at low temperature.

The EL2 defect and its metastable state. The electrical and optical properties and parameters of the EL2 defect are well known (Table 1)[9, 10]. An unusual property of this defect is the existence of a metastable state at low temperature called EL2* which is optically and electrically inactive [15]. The transfer of the defect from the neutral state EL2 ${ }^{0}$ to the metastable state is optically induced by photons with an energy around $1.18 \mathrm{eV}$ [15]. With this transfer, known as photoquenching of EL2, a lot of the characteristics of EL2 disappear such as below band-gap absorption [19], electron paramagnetic resonance [20] or diffraction efficiency in PRE measurements [6]. The transfer from EL2 ${ }^{0}$ to EL2 ${ }^{*}$ is optically induced with a cross-section $S_{n}^{*}$ [15], whose absolute value at the maximum (experiments were performed at this maximum) is about the tenth of the electron photoionization cross-section 
$S_{n}$. As there is no evidence of any temperature variation, we assume $S_{n}^{*}$ to be constant. The recovery is induced both thermally with a recovery rate $\mathrm{r}^{*}[15]$ and optically with an optical recovery cross-section $S_{r}^{*}[16]$. The spectrum of $S_{r}^{*}$ is characterized by two bands centered at $0.85 \mathrm{eV}$ and $1.45 \mathrm{eV}$. Between these two maxima the cross-section seems to go to a minimum for our energy of interest $(1.18 \mathrm{eV})$ [16]. No absolute value of this cross-section is accessible, nevertheless we can estimate the ratio $S_{n}^{*} / S_{r}^{*}$ from the experimental curves of ref.[16]. The recovery of the quenched absorption measured at $1.18 \mathrm{eV}$ is about $1 \%$. This absorption recovery can be written as a function of the different cross-sections as $\frac{S_{r}^{*}}{S_{r}^{*}+S_{n}^{*}}$ [21] which gives an estimation for the ratio $S_{n}^{*} / S_{r}^{*} \approx 100$. The optical recovery cross-section was also found to be thermally activated [22]. In our study the temperature range, where the metastable state is studied, is between 90 and $150 \mathrm{~K}$, a range where $S_{r}^{*}$ varies only slightly with temperature [22] (a factor 2 to 3), so we neglect this temperature effect to simplify the present study. So we see that all the parameters that characterize the EL2 defect and its metastable state are well known from literature, including their temperature dependence. We will use these parameters to predict the behavior of the photorefractive effect in undoped GaAs at low temperature.

Theoretical background. To establish a theoretical expression for the photorefractive gain, we extend the band transport model [23, 24], including the metastable state of EL2. We solve it in a classical manner in steady-state without applied field [25]. The zeroth order terms give the concentrations of the different states of the EL2 defect and of free carriers and the first order terms give the modulated space charge field and the eventual absorption grating components.

The concentrations in the different species of EL2 are $\left[E L 2^{0}\right]=A^{\prime *}\left([E L 2]-\left[E L 2^{+}\right]\right)$ and $\left[E L 2^{*}\right]=\left(1-A^{\prime *}\right)\left([E L 2]-\left[E L 2^{+}\right]\right)$with $A^{\prime *}=\frac{r^{*}+S_{r}^{*} I_{0}}{r^{*}+S_{r}^{*} I_{0}+S_{n}^{*} I_{0}}$, the EL2+ concentration will be given by a second order equation (in the case where the free electron concentration is negligible) : $\left[E L 2^{+}\right]^{2}-\left[E L 2^{+}\right]\left[\left(\frac{\beta_{p}+S_{p} I_{0}}{\gamma_{p} A^{\prime *}}\right)+\left(N_{A}-N_{D}+[E L 2]\right)\right]+\left(N_{A}-N_{D}\right)[E L 2]=0$. The temperature dependency of this equation occurs through the first term of the second member of the equation and particularly $\mathrm{A}^{\prime *}$. Indeed $\mathrm{A}^{\prime *}$ depends on the recovery rate $\mathrm{r} *$ (Table 1 ). At high temperature $\mathrm{r}^{*}$ goes to a value much greater than $\left(S_{r}^{*} I_{0}+S_{n}^{*} I_{0}\right)$ and $\mathrm{A}^{\prime *}$ equals approximately 1 . When temperature decreases $\mathrm{r}^{*}$ goes to zero and $\mathrm{A}^{\prime *}$ decreases to a limit $A^{\prime^{*}}=S_{r}^{*} /\left(S_{r}^{*}+S_{n}^{*}\right)$ which goes to zero below $77 \mathrm{~K}$ as $S_{r}^{*}$ decreases with temperature [22]. With these equations we can calculate the temperature variation of the populations in the temperature range 77-300K (Fig.3). From these curves we see an important feature of the EL2 quenching in GaAs, although $\mathrm{A}^{\prime *}$ has decreased by a factor 100 , when passing from $300 \mathrm{~K}$ to $77 \mathrm{~K}$ (which means that the EL2 ${ }^{0}$ concentration has decreased by the same factor), 
the EL2+ concentration has not changed $\left(\left\lfloor E L 2^{+}\right\rfloor=\left(N_{A}-N_{D}\right)\right)$. We have quenched only the neutral part of EL2 and not the ionized part. This is easy to understand physically as the transfer from EL2 ${ }^{+}$to the metastable state is a transfer in two steps : firstly, the generation of a hole is accompanied by the transformation of EL2 ${ }^{+}$to EL2 ${ }^{0}$, then EL2 ${ }^{0}$ is transferred to EL2* Then there is competition between the lifetime of holes and the lifetime of the metastable state, resulting in a reduced efficiency of the transfer from EL2 ${ }^{+}$to EL2 ${ }^{*}$. We can also see on Fig. 3 that the concentration of free electrons stays negligible and that free holes are generated at low temperature by the quenching of EL2 ${ }^{+}$.

The spatially modulated space charge field $E_{1}$ is calculated from the first order equations [25] :

$$
E_{1}=\frac{-i m\left(\frac{k_{B} T}{e}\right) k}{1+A^{\prime *} \frac{k^{2}}{k_{0}^{2}}}\left[\xi(k)-\left(1-A^{\prime *}-B^{\prime *}\right)\right]
$$

with $\xi(k)=\frac{\alpha_{n}\left(k^{2}+\kappa_{p}^{2}\right)-\alpha_{p}\left(k^{2}+\kappa_{n}^{2}\right)}{A_{n} \alpha_{n}\left(k^{2}+\kappa_{p}^{2}\right)+A_{p} \alpha_{p}\left(k^{2}+\kappa_{n}^{2}\right)}$ the electron-hole competition coefficient [24] and $B^{\prime *}=\frac{S_{n}^{*} S_{r}^{*} I_{0}^{2} A^{\prime *}}{\left(r^{*}+S_{r}^{*} I_{0}\right)^{2}} . A_{n}=\frac{\beta_{n}+S_{n} I_{0}}{S_{n} I_{0}}, A_{p}=\frac{\beta_{p}+S_{p} I_{0}}{S_{p} I_{0}}$ give the influence of the thermal emission of carriers from EL2 at high temperature. $\alpha_{n}=S_{n}\left\lfloor E L 2^{0}\right\rfloor, \alpha_{p}=S_{p}\left\lfloor E L 2^{+}\right\rfloor$are the parts of the absorption that create electrons and holes, respectively. $\kappa_{n}^{2}=\frac{e}{k_{B} T} \frac{\gamma_{n}\left[E L 2^{+}\right]}{\mu_{n}}, \kappa_{p}^{2}=\frac{e}{k_{B} T} \frac{\gamma_{p}\left[E L 2^{0}\right]}{\mu_{p}}$ are the inverse squared of the diffusion lengths of electrons and holes. Finally, $k_{0}^{2}=\frac{e^{2}}{\varepsilon k_{B} T} \frac{\left[E L 2^{+}\left[E L 2^{0}\right]\right.}{[E L 2]}$ is the inverse squared of the Debye screening length. The different concentrations $\left[E L 2^{+}\right]$and $\left[E L 2^{0}\right]$ are given by the zeroth order solution of the equations, as seen previously.

The influence of the metastable state of EL2 appears in the k dependency of $\mathrm{E}_{1}$ with the term $k_{0}^{2} / A^{\prime *}$. Taking into account zeroth order equations, we obtain : $\frac{k_{0}^{2}}{A^{\prime *}}=\frac{e^{2}}{\varepsilon k_{B} T} \frac{\left[E L 2^{+}\right]\left([E L 2]-\left[E L 2^{+}\right]\right)}{[E L 2]}$. As [EL2+] stays constant between $77 \mathrm{~K}$ and $300 \mathrm{~K}$, we see that the term $k_{0}^{2} / A^{\prime *}$ keeps the value it has at $300 \mathrm{~K}$. At lower temperature [EL2+] decreases (as $S_{r}^{*}$ decreases) and $k_{0}^{2} / A^{\prime *}$ decreases and goes to zero, decreasing $\mathrm{E}_{1}$. Then the only remaining influence of the metastable state between $77 \mathrm{~K}$ and $300 \mathrm{~K}$ is through the term of "hole-electron" competition, i.e. through the value of $R=\xi(k)-\left(1-A^{\prime^{*}}-B^{\prime *}\right)$. We will now discuss the variation of this parameter with temperature, by considering its two terms independently to clarify the situation. Considering the values of the different parameters we can make the usual approximation at room temperature : $\kappa_{n}^{2}, \kappa_{p}^{2}<<k^{2}$. Moreover, as thermal emission is negligible for temperatures below $300 \mathrm{~K}$ we have $A_{n}=A_{p}=1$ and $\xi(k)$ reduces to 
$\xi_{0}=\frac{\alpha_{n}-\alpha_{p}}{\alpha_{n}+\alpha_{p}}$. In our material, we have $\left[\mathrm{EL}^{0}\right] \approx\left[\mathrm{EL} 2^{+}\right]$which means that we have an electron-hole competition $0<\xi_{0}<1$ [1]. With decreasing temperature (around 150K) we are quenching EL2 ${ }^{0}$ (Fig.3) and the ratio becomes [EL2 $2^{0} /\left[\mathrm{EL}_{2}{ }^{+}\right] \approx 1 / 100$ which means that $\xi_{0}$ changes its sign and becomes close to -1 (holes becomes the majority carriers). The second term of R can be rewritten $\left(1-A^{\prime *}-B^{\prime *}\right)=\frac{S_{n}^{*} I_{0} r^{*}}{\left(r^{*}+S_{r}^{*} I_{0}+S_{n}^{*} I_{0}\right)\left(r^{*}+S_{r}^{*} I_{0}\right)}$. At room temperature $\mathrm{r}^{*} \gg S_{n}^{*} I_{0}, S_{r}^{*} I_{0}$ then $\left(1-A^{\prime *}-B^{\prime *}\right) \approx 0$, at low temperature $\mathrm{r}^{*}$ goes to zero then $\left(1-A^{\prime *}-B^{\prime *}\right)$ goes to zero, which means that $\left(1-A^{\prime \prime}-B^{\prime *}\right)$ goes through a maximum when we decrease temperature. If we suppose that the only temperature varying parameter is $r^{*}$ (we suppose that $\mathrm{T}>77 \mathrm{~K}$ and then $S_{r}^{*}$ is constant), the maximum is obtained for $r_{M}^{*}=I_{0} \sqrt{S_{r}^{*}\left(S_{r}^{*}+S_{n}^{*}\right)}$, the maximum value being $\left(1-A^{\prime *}-{B^{\prime}}^{*}\right)_{M}=\frac{S_{n}^{*}}{\left(\sqrt{S_{r}^{*}}+\sqrt{S_{r}^{*}+S_{n}^{*}}\right)^{2}}$. From the value of $r_{M}^{*}$ (Table 1) we deduce the temperature at which the maximum occurs (around $140 \mathrm{~K}$ in our case). Firstly, we remark that $r_{M}^{*}$ depends on the incident illumination. When we decrease illumination, $r_{M}^{*}$ decreases and the temperature where the peak is located decreases. Secondly, we want to point out that the maximum of the expression $\left(1-A^{\prime *}-B^{\prime *}\right)_{M}$ is close to 1 considering the value of the ratio $S_{n}^{*} / S_{r}^{*}$ to be 100 , but it is the closer to one, the higher this ratio.

If we now consider both terms of $\mathrm{R}$ together, we obtain for $\mathrm{R}$ a value of about -2 at the peak, which means that the gain is twice as large than the maximum gain obtainable in a photorefractive material without applied field considering Kukhtarev's model with only one type of carrier. At high grating spacing when $k^{2}<<k_{0}^{2} / A^{\prime *}$ we obtain for the space charge field $E_{1}=2 i m k\left(k_{B} T / e\right)=2 i m E_{d}$ where $\mathrm{E}_{\mathrm{d}}$ is the diffusion field. The enhancement of the gain due to the metastable state can be of a factor 2 in ideal conditions. This enhancement is characteristic for the model we develop here. All band transport models derived from Kukhtarev's model including both carriers [24], or secondary traps [2, 3, 26] predict a reduction of the photorefractive effect. In the real case the effect of temperature is more complicated, as both quantities $\xi_{0}$ and $\left(1-A^{\prime \prime^{*}}-B^{\prime \prime}\right)$ vary together with temperature. Nevertheless all the features predicted are preserved, as shown on the calculated theoretical curve (Fig.1), particularly the possibility to have $|R|$ higher than one, even if the maximum value of -2 is hardly obtainable.

In the same way that first order equations give the space charge field they also give the modulated charge redistribution that causes the absorption grating. We can calculate [25]: $\alpha_{1}=\left[S_{p}-\left(S_{n}+S_{n}^{*}\right) A^{\prime *}+S_{r}^{*}\left(A^{\prime *}-1\right)\right]\left(i \frac{k \varepsilon}{e} E_{1}\right)+m\left(1-A^{\prime *}-B^{\prime *}\right)\left(S_{r}^{*}-S_{n}-S_{n}^{*}\right)\left[E L 2^{0}\right]$

The first term corresponds to the classical absorption grating term that exists at room temperature and is very small. The second term is more interesting as it does not exist at room temperature. As it is proportional to $\left[\mathrm{EL}^{0}\right]$ and to $\left(1-A^{\prime *}-B^{\prime *}\right)$, we see it to a peak around 
$140 \mathrm{~K}$. So the absorption grating goes through a maximum (up to $0.2 \mathrm{~cm}^{-1}$ ) as shown on the calculated curves of the absorption grating strength (Fig.2).

Conclusion. Photorefractive two beam coupling experiments performed at low temperature in undoped GaAs reveal peculiar characteristics of this material such as a reversal of the sign of the photorefractive gain, strong enhancement of the value of this photorefractive gain and a peak of the absorption grating strength at low temperature. These results are explained theoretically by introducing the well known metastable state of the EL2 defect in the photorefractive model that appears at low temperature. All experimental characteristics of the photorefractive effect are perfectly described by this model, in particular the fact that space charge fields higher than the diffusion field are observed.

Acknowledgments. $\mathrm{Ph}$. Delaye wants to thank the Universität Osnabrück for its financial support and Dr. R. Rupp for his welcome at the Fachbereich Physik.

\section{REFERENCES :}

[1] Ph. Delaye, L.A. de Montmorillon, H.J. von Bardeleben, G.Roosen. Appl. Phys. Lett. 64, 2640 (1994)

[2] P. Delaye, P. U. Halter, G. Roosen, J. Opt Soc. Am. B 7, 2268 (1990).

[3] R.S.Rana, D.D.Nolte, R.Steldt,E.M.Monberg, J. Opt Soc. Am. B 9, 1614 (1992).

[4] J.C.Launay, V.Mazoyer, M.Tapiero, J.P.Zielinger, Z.Guellil, Ph.Delaye, G.Roosen, Appl. Phys. A 55 , 33 (1992).

[5] D.D.Nolte, D.H.Olson, A.M.Glass, Appl. Phys. Lett. 56, 163 (1990).

[6] D.D.Nolte, D.H.Olson, A.M.Glass, Phys. Rev. B 40, 10650 (1989).

[7] A.L.Khromov, M.P.Petrov. Opt. Commun. 88, 315 (1992).

[8] B.Sugg, F.Kahmann, R.A.Rupp, Ph.Delaye, G.Roosen. Opt. Commun. 102, 6 (1993).

[9] J.C.Bourgoin, H.J.von Bardeleben, D.Stiévenard. J. Appl. Phys. 64, R65 (1988).

[10] M.O.Manasreh, D.W.Fischer, W.C.Mitchel, Phys. Stat. Sol. b 154, 11 (1989).

[11] P.Silverberg, P.Omling, L.Samuelson. Appl. Phys. Lett. 52, 1689 (1988).

[12] V.Y.Prinz, S.N.Rechkunov Phys. Stat. Sol. b 118, 159 (1983).

[13] J.S.Blakemore. J. Appl. Phys. 53, R123 (1982).

[14] J.S.Blakemore. J. Phys.Chem. Solids 49, 627 (1988).

[15] G.Vincent, D.Bois, A.Chantre, J. Appl. Phys. 53, 3643 (1982).

[16] M.O.Manasreh, D.W.Fisher.Phys. Rev. B 40, 11756 (1989).

[17] D.T.F. Marple, J. Appl. Phys. 35, 1241 (1964).

[18] C.A. Berseth, C. Wuethrich, F.K. Reinhart, J. Appl. Phys. 71, 2821 (1992).

[19] G.M. Martin. Appl. Phys. Lett. 39, 747 (1981).

[20] H.J. von Bardeleben, D. Stiévenard, D. Deresmes, A. Huber, J.C. Bourgoin. Phys. Rev. B 34, 7192, (1986)

[21] J.C.Parker, R.Bray. Phys. Rev. B 37, 6368 (1988).

[22] D.W.Fisher, M.O.Manasreh. Appl. Phys. Lett. 54, 2018 (1989). 
[23] N.V. Kukhtarev, V.B. Markov, S.G. Odulov, M.S. Soskin, V.L. Vinetskii, Ferroelectrics 22, 949 (1979); 22, 961 (1979).

[24] F.P. Strohkendl, J.M.C. Jonathan, R.W. Hellwarth, Opt. Lett. 11, 312 (1986).

[25] Ph.Delaye, B. Sugg. Submitted to Phys. Rev B.

[26] P. Tayebati. J. Opt. Soc. Am. B 9, 415 (1992). 


\begin{tabular}{|c|c|c|}
\hline name & value & reference \\
\hline $\begin{array}{l}\mathrm{S}_{\mathrm{n}} \text { electron photoionization cross-section } \\
\text { at } 1.06 \mu \mathrm{m}\left(\mathrm{cm}^{2}\right)\end{array}$ & $1 \times 10^{-16}$ & {$[11]$} \\
\hline $\begin{array}{l}\text { Sp hole photoionization cross-section at } \\
1.06 \mu \mathrm{m}\left(\mathrm{cm}^{2}\right)\end{array}$ & $3 \times 10^{-17}$ & [11] \\
\hline $\begin{array}{l}\sigma_{n} \text { capture cross-section of electrons } \\
\left(\mathrm{cm}^{2}\right)\end{array}$ & $5 \times 10^{-19}+6 \times 10^{-15} \exp \left(-0.0566 \frac{e}{k_{B} T}\right)$ & [9] \\
\hline$\sigma_{p}$ capture cross-section of holes $\left(\mathrm{cm}^{2}\right)$ & $2 \times 10^{-18}$ & [12] \\
\hline$v_{\text {nth }}$ thermal velocity of electrons $\left(\mathrm{cm} \cdot \mathrm{s}^{-1}\right)$ & $4.4 \times 10^{7}\left(\frac{T}{300}\right)^{\frac{1}{2}}$ & {$[13]$} \\
\hline$v_{\text {pth }}$ thermal velocity of holes $\left(\mathrm{cm} \cdot \mathrm{s}^{-1}\right)$ & $1.65 \times 10^{7}\left(\frac{T}{300}\right)^{\frac{1}{2}}$ & [13] \\
\hline$\gamma_{\mathrm{n}(\mathrm{p})}$ recombination coefficient $\left(\mathrm{cm}^{3} \cdot \mathrm{s}^{-1}\right)$ & $\sigma_{\mathrm{n}(\mathrm{p})} \cdot \mathrm{v}_{\mathrm{n}(\mathrm{p}) \mathrm{th}}$ & \\
\hline$\mu_{\mathrm{n}}$ electron mobility $\left(\mathrm{cm}^{2} \cdot \mathrm{V}^{-1} \cdot \mathrm{s}^{-1}\right)$ & $8000\left(\frac{T}{300}\right)^{2.3}$ & {$[13]$} \\
\hline$\mu_{\mathrm{p}}$ hole mobility $\left(\mathrm{cm}^{2} \cdot \mathrm{V}^{-1} \cdot \mathrm{s}^{-1}\right)$ & $320\left(\frac{T}{300}\right)^{2.3}$ & {$[13]$} \\
\hline $\begin{array}{l}\beta_{\mathrm{n}} \text { electron thermal emission coefficient } \\
\left(\mathrm{s}^{-1}\right)\end{array}$ & $2.83 \times 10^{7} T^{2} \exp \left(-0.814 \frac{e}{k_{B} T}\right)$ & {$[14]$} \\
\hline$\beta_{\mathrm{p}}$ hole thermal emission coefficient $\left(\mathrm{s}^{-1}\right)$ & $3.3 \times 10^{4} T^{2} \exp \left(-0.813 \frac{e}{k_{B} T}\right)$ & [14] \\
\hline $\mathrm{r}^{*}$ recovery rate of the metastabe state $\left(\mathrm{s}^{-1}\right)$ & $2 \times 10^{11} \exp \left(-0.30 \frac{e}{k_{B} T}\right)$ & [15] \\
\hline $\begin{array}{l}S_{n}^{*} \text { metastable state generation optical } \\
\text { cross-section }\left(\mathrm{cm}^{2}\right)\end{array}$ & $1 \times 10^{-17}$ & {$[15]$} \\
\hline $\begin{array}{l}S_{r}^{*} \text { recovery optical cross-section of the } \\
\text { metastable state }\left(\mathrm{cm}^{2}\right)\end{array}$ & $\approx 1 \times 10^{-19}$ & {$[16]$} \\
\hline$\varepsilon_{\mathrm{r}}$ relative dielectric constant & $12.4\left(1+1.2 \times 10^{-4} \mathrm{~T}\right)$ & [13] \\
\hline $\mathrm{n}_{0}$ refractive index & $\begin{array}{c}n_{0}^{2}=A+\left(\frac{n_{\infty}^{2}-A}{1-B(h v)^{2}}\right) \\
\mathrm{A}=7.10 \\
\mathrm{~B}=0.18(\mathrm{eV})^{-2} \\
n_{\infty}=3.255\left(1+4.5 \times 10^{-5} T\right) \\
\text { h } v \text { in eV }\end{array}$ & {$[13,17]$} \\
\hline $\mathrm{r}_{41}$ electrooptic coefficient $\left(\mathrm{pm} . \mathrm{V}^{-1}\right)$ & 1.72 & [18] \\
\hline
\end{tabular}

TABLE 1

Parameters of the EL2 defect used in the theoretical calculations. 


\section{FIGURE CAPTIONS}

Figure 1: Experimental photorefractive gain $\Gamma(+)$ as a function of temperature for sample D2. The straight line represents the calculated photorefractive gain (see text for calculation parameters). The dashed lines represents the theoretical gain for a one carrier model corresponding to a space-charge field of amplitude $\pm E_{d}$.

Figure 2: Experimental absorption energy transfer $\Delta \alpha(+)$ as a function of temperature for sample D2. The straight line represents the calculated absorption grating strength (see text for calculation parameters).

Figure 3 : Calculated concentration of the different species present in undoped GaAs as a function of the temperature (illumination $\mathrm{I}=60 \mathrm{~mW} \cdot \mathrm{cm}^{-2}$ ).

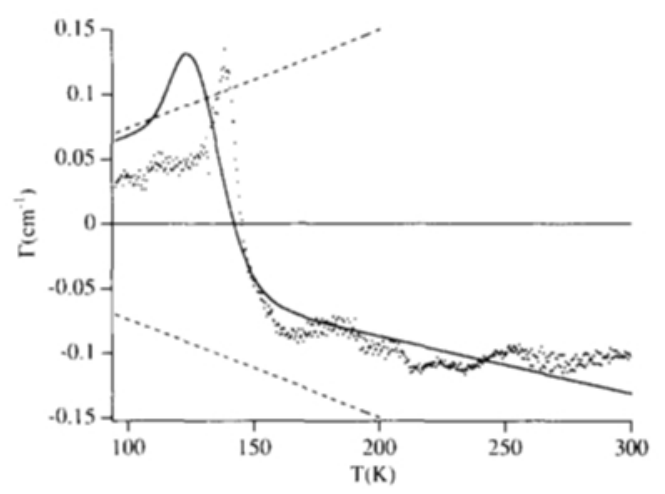

Figure 1

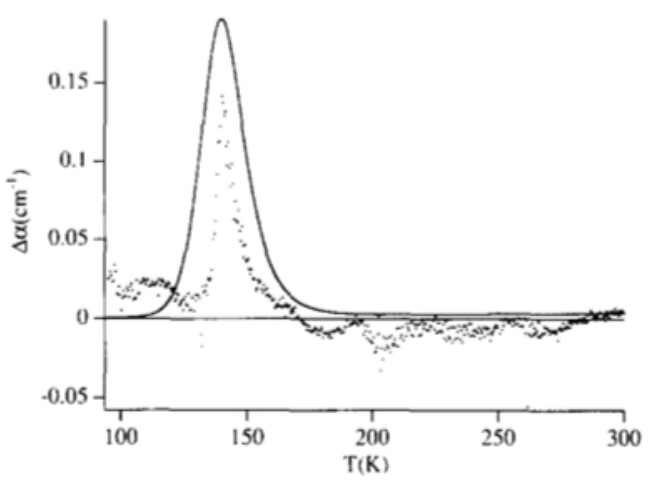

Figure 2 


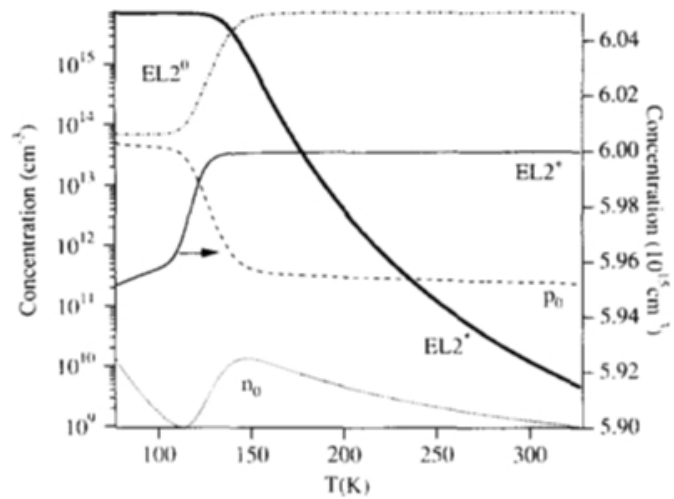

Figure 3 